\title{
Attitude of health care providers in Abia State, Nigeria, to people living with HIV and AIDS
}

\author{
Charles Adisa', Ugochukwu Onyeonoro ${ }^{1 *}$, Aniele Agu' ${ }^{1}$, Ndukauba Eleweke1', Umezurike Chisara ${ }^{2}$ \\ From $12^{\text {th }}$ International Conference on Malignancies in AIDS and Other Acquired Immunodeficiencies \\ (ICMAOI) \\ Bethesda, MD, USA. 26-27 April, 2010
}

\section{Background}

In pursuit of the global commitment of universal access to HIV services, there has been rapid scale up of HIV programmes including care and support in Nigeria in the past few years. Consequently, more health care providers are increasingly being involved in the provision of HIV services; this however increases their risk of exposure to HIV infection. Most people accessing HIV services are also at risk of developing malignancies because they often present late as a result of stigma. Care providers attitude towards PLWHA has been shown to be the most important factor influencing uptake of HIV services [1]. The objective of this study is to ascertain health care workers knowledge of HIV and their attitude towards PLWHAs in Abia State, Nigeria.

\section{Methodology}

A cross-sectional, descriptive study, involving a total of 300 health care workers selected using stratified sampling technique from the list of registered health care workers in the State. Responses were elicited from them using semi-structured self-administered questionnaire on socio-demographic characteristics, knowledge of HIV/AIDS and attitude towards PLWHAs. Data collected was analyzed using Epi-info 3.5.1 version. IRB approval was obtained from Abia State University.

\section{Result}

The respondents included 135 nurses (52\%), 56 doctors (21.7\%), others were pharmacists, laboratory scientists and medical records officers. Almost all know that HIV is a blood transmissible infection. Over $50 \%$ believe that HIV transmission in health care settings is predominantly by sexual intercourse, while $40 \%$ of them consider recapping of

\footnotetext{
* Correspondence: adisayinka@yahoo.com

${ }^{1}$ Abia State University, Aba, Nigeria

Full list of author information is available at the end of the article
}

needles as an important measure in preventing HIV transmission. 13\% of them feel that their work do not expose them to the risk of acquiring HIV, and $40 \%$ do not think that increased uptake of HIV services increases their chance of acquiring HIV. Majority of them provide one form of HIV services in their facility or the other, but their facilities lack enough provisions to protect them from HIV infection. However, most health workers in the state expressed willingness to care for PLWHAs, admit them into their facility, as well as work with an HIV positive colleague. However, less than $35 \%$ are not willing to share a meal with HIV person, buy food from a HIV positive shopkeeper.

\section{Conclusion}

These findings underscores the need to further educate health care providers in Abia State Nigeria on the risk of occupational exposure to HIV transmission, so as to improve their attitude towards PLWHA, which in turn may result in increased uptake of HIV services.

\section{Acknowledgements}

This article has been published as part of Infectious Agents and Cancer Volume 5 Supplement 1, 2010: Proceedings of the $12^{\text {th }}$ International Conference on Malignancies in AIDS and Other Acquired

Immunodeficiencies (ICMAOI).The full contents of the supplement are available online at http://www.biomedcentral.com/1750-9378/5?issue=S1.

\section{Author details}

${ }^{1}$ Abia State University, Aba, Nigeria . ${ }^{2}$ Christian Hospital, Nlagu, Nigeria.

Published: 11 October 2010

\section{Reference}

1. Gobopamang Letamo: The discriminatory attitudes of health workers against people living with HIV. PLoS Med 2005, 2(8):e261.

\section{doi:10.1186/1750-9378-5-S1-A5}

Cite this article as: Adisa et al: Attitude of health care providers in Abia State, Nigeria, to people living with HIV and AIDS. Infectious Agents and Cancer 2010 5(Suppl 1):A5. 